\title{
ANÁLISE DO LEAD TIME NOS PROCESSOS LOGÍSTICOS DE UMA REDE VAREJISTA DE FLORES
}

\section{ANALYSIS OF LEAD TIME IN LOGISTICS PROCESSES OF A FLOWER RETAILER NETWORK}

\author{
Luciana Torres Correia de Mello*E-mail: lucianatcmello@yahoo.com.br \\ Hugo Carlos Mansano Dornfeld* E-mail: hugo dornfeld@yahoo.com \\ Givaldo Guilherme dos Santos* E-mail: ggs1959@gmail.com \\ Débora Passos* E-mail: deborinhapassos@gmail.com \\ Rafael Ribeiro* E-mail: 18rafaelr@gmail.com \\ Moacir Godinho Filho* E-mail: moacir@dep.ufscar.br \\ *Universidade Federal de São Carlos (UFSCar), São Carlos, SP
}

\begin{abstract}
Resumo: $O$ mercado de flores no Brasil necessita de reestruturação para conseguir oferecer produtos sensíveis com maior qualidade para o consumidor. Essa reestruturação permitirá que as flores cheguem ao consumidor mais rapidamente e com mais tempo de durabilidade. $O$ objetivo deste estudo foi analisar o lead time dos processos logísticos de uma rede varejista de flores com sede na cidade de Campinas/SP, utilizando a ferramenta MCT - Manufacturing Critical-path Time, da abordagem QRM - Quick Response Manufacturing. Algumas ferramentas auxiliaram a pesquisa, como Fluxograma, Mapa de Fluxo de Valor, Diagrama de Ishikawa e Brainstorming. Os dados coletados relacionados aos tempos de processamento das operações levantam características dos processos logísticos envolvidos na distribuição da matéria-prima, desde a sua aquisição até a entrega em cada filial. Ao fim da pesquisa foi possível propor mudanças nos locais de compras das flores e no modo de distribuição para as lojas, simulando a redução no lead time de aproximadamente $80 \%$.
\end{abstract}

Palavras-chave: QRM - Quick Response Manufacturing. MCT - Manufacturing Critical-path Time. Mercado de flores. Transporte.

\begin{abstract}
The flower market in Brazil needs restructuring to be able to offer delicate products with higher quality for the consumer. This restructuring will allow the flowers reach the customer faster and with longer durability. The aim of this study was to analyze the lead time of logistics processes of a flower retailer network with headquarters in Campinas/SP using the tool Manufacturing Critical-path Time of the Quick Response Manufacturing approach. We also use the tools Flowchart, Value Stream Map, Ishikawa Diagram and Brainstorming. The collected data related to the operations processing times showed characteristics of logistics processes involved in the distribution of raw material, from its acquisition to delivery at each branch office. At the end of the research was possible to propose changes in the shopping places of flowers and distribution mode to stores, simulating the reduction in the lead time of approximately $80 \%$.
\end{abstract}

Keywords: Quick Response Manufacturing. Manufacturing Critical-path Time. Flower Market. Transport. 


\section{INTRODUÇÃO}

O setor produtivo de flores e plantas ornamentais no Brasil vem consolidando posições mais relevantes no agronegócio nacional, destacando-se como atividade economicamente crescente, que além de agregar alto potencial de expansão futura, representa também uma das principais atividades geradoras de emprego e renda para pequenos produtores em todo o país (JUNQUEIRA; PEETZ, 2014).

$O$ mercado de flores brasileiro apresenta-se como um agregador no indicador do PIB do agronegócio, fortalecendo o setor primário até o setor terciário da economia (ABAFEP, 2016). É um setor que possui ainda grande importância financeira (JUNQUEIRA; PEETZ, 2014), requerendo avaliação no lead time desta cadeia produtiva e suas consequências, visto que o produto é altamente perecível e há várias etapas de seu processo até a chegada ao consumidor final, como a compra do produto, o transporte em diversas etapas até a chegada ao cliente final e os manuseios operacionais.

Em geral, o lead time é visualizado como o tempo de uma companhia responder ao pedido do seu consumidor, mas aqui o lead time se refere ao tempo total de receber a informação e/ou material até concluir a ordem do pedido, considerando que não há ação feita antes do tempo (TUBINO; SURI, 2000) ou ainda o tempo que decorre desde a criação da ordem pelo cliente até que o produto/serviço seja efetivamente recebido por ele (GODINHO FILHO; HAYASHI; RUFO, 2013). Os impactos positivos procedentes da redução do lead time se tornou um benefício para as empresas e gera uma maior satisfação aos seus clientes (TUBINO; SURI, 2000), sobretudo quando consegue reduzir o tempo de entrega do produto. Sarkar et al. (2015) também relataram melhor nível de satisfação do cliente com a redução do lead time.

Apesar de esse mercado ser promissor (IBRAFLOR, 2015), alguns pontos de melhorias são necessários, como o fortalecimento e profissionalização crescente das vendas de flores e plantas ornamentais pelos supermercados; continuidade do desenvolvimento do mercado de paisagismo e jardinagem; reorganização da base produtiva da floricultura nacional, com a continuidade do fortalecimento e estruturação dos polos regionais; busca permanente de agregação de novos produtos, serviços e qualidade de mercadorias e redirecionamentos, novos rumos e ritmos no desenvolvimento das políticas setoriais de apoio e fomento, decorrentes dos rearranjos político-institucionais (JUNQUEIRA; PEETZ, 2014).

Observa-se que a maioria dos estudos da abordagem QRM está relacionada a grandes empresas, excluídas as micros e pequenas, bem como as empresas de serviço (PIOVEZAN; LAURINDO; CARVALHO, 2008). No entanto, pequenas e médias empresas também necessitam planejar suas estratégias, respeitando suas peculiaridades e ramo de atividade. Este artigo tem potencial para contribuir para o desenvolvimento da literatura científica e da aplicação do QRM em empresas do 
setor de serviço que desejam reduzir o lead time e se tornarem mais flexíveis e competitivas.

Assim, o objetivo geral do presente estudo foi analisar os processos logísticos de uma rede varejista de flores buscando propor ações para reduzir o lead time com base na ferramenta MCT - Manufacturing Critical-path Time. Os objetivos específicos foram: (i) mensurar o grau de perdas e desperdícios promovidos pelo lead time no ciclo do produto desde a sua aquisição até a distribuição nas filiais; e (ii) identificar os principais fatores dentro da abordagem QRM que podem contribuir para a redução do lead time na cadeia logística.

O artigo está organizado da seguinte forma. Além dessa seção de caráter introdutório, o tópico 2 abordará uma revisão geral a respeito do mercado de flores no Brasil e do QRM, que foi a abordagem utilizada para realizar a pesquisa proposta. A seção 3 demonstra os métodos utilizados no decorrer da pesquisa e o tópico 4 descreve sucintamente a empresa estudada, de modo a entender o contexto em que ela se encontra, as causas de longos tempos, as propostas de melhoria e os resultados encontrados. Em seguida, no tópico 5, são explanadas as considerações finais do estudo.

\section{REVISÃO BIBLIOGRÁFICA}

\subsection{O mercado de flores no Brasil}

O cultivo profissional e o comércio no mercado de flores são recentes no Brasil. A cadeia produtiva de flores e plantas ornamentais movimentou o valor de $R \$$ 5,22 bilhões no ano de 2013, apresentando um crescimento de 8,3\% sobre os resultados obtidos no ano de 2012 (JUNQUEIRA; PEETZ, 2014). Desde 2013, o mercado vem crescendo de 12 a 15\% por ano. Segundo IBRAFLOR (2015), o país possui 8 mil produtores de flores e plantas que cultivam mais de 350 espécies com cerca de 3 mil variedades, respondendo por mais de 215 mil empregos diretos pertinentes à produção, 120 mil no varejo e aproximadamente 16 mil relativos à distribuição e funções de apoio.

Em termos regionais, o Sudeste concentra a maior parcela do número total de produtores $(53,3 \%)$, sendo este o principal polo florícola nacional. Considerando os produtos de floricultura, especialmente as flores, folhagens e plantas envasadas, também é na região Sudeste que se concentra o cultivo, com $83,48 \%$, com liderança de orquídeas, bromélias, lírios, violetas, entre outras espécies. A essa região seguem Sul $(8,12 \%)$, Nordeste $(6,87 \%)$, Centro-Oeste $(1,14 \%)$ e Norte $(0,39 \%)$ (JUNQUEIRA; PEETZ, 2014).

O estado de São Paulo possui grande participação no mercado brasileiro de flores (SILVA; PAIVA; SANTOS, 2015), sendo o município de Holambra o maior produtor no Brasil. O destaque nacional está também no fato de Holambra abrigar, 
em território latino-americano, a maior cooperativa de comercialização de flores, Cooperativa Veiling (BUENO, 2015; KNAAP, 2014), trabalhando em sistema de leilão.

O sistema de comercialização baseado em leilão gera agilidade, transparência e a necessidade de produtos padronizados (IBRAFLOR, 2015). O leilão ocorre em sentido inverso, ou seja, inicia-se com o preço máximo e reduz à medida que se passa o tempo (SILVA; PAIVA; SANTOS, 2015). Técnicas adequadas possibilitam prolongar a vida útil das flores, aumentando o período de comercialização de produtos de alta qualidade e, consequentemente, proporcionam maiores lucros (SONEGO; BRACKMANN, 1995).

\subsection{QRM - Quick Response Manufacturing}

Atualmente, o modelo econômico tem conduzido as várias alterações na área de negócios. O mercado além de exigir maior qualidade, maior mix de produtos e menor custo, também está exigindo a entrega de produtos em intervalos de tempo cada vez menores. Para muitas empresas, a melhoria da competitividade implica na necessidade de foco em velocidade (GODINHO FILHO et al., 2011). Inerentes a estas novas exigências existe um paradigma específico chamado QRM - Quick Response Manufacturing (GODINHO FILHO; SAES, 2013), que foi criado por Rajan Suri em 1998, e vem ganhando espaço e sendo implementado com sucesso por diversas empresas, principalmente nos Estados Unidos e na Europa (GODINHO FILHO; HAYASHI; RUFO, 2013).

O QRM é definido como uma estratégia voltada para a redução de lead time em todas as operações de uma empresa, principalmente em um ambiente com uma linha de produção diversificada e variedades de produtos distintos, mas ainda envolvendo os ambientes interno e externo (SURI, 2010). Externamente, significa responder às necessidades dos clientes, fornecendo respostas rápidas aos novos projetos. Internamente, significa a redução de lead time para todas as tarefas, melhoria da qualidade, redução de custos e aumento na velocidade de resposta (FERNANDES; CARMO-SILVA, 2006). A Figura 1 apresenta uma visão geral do QRM. 
Figura 1 - Visão geral do QRM

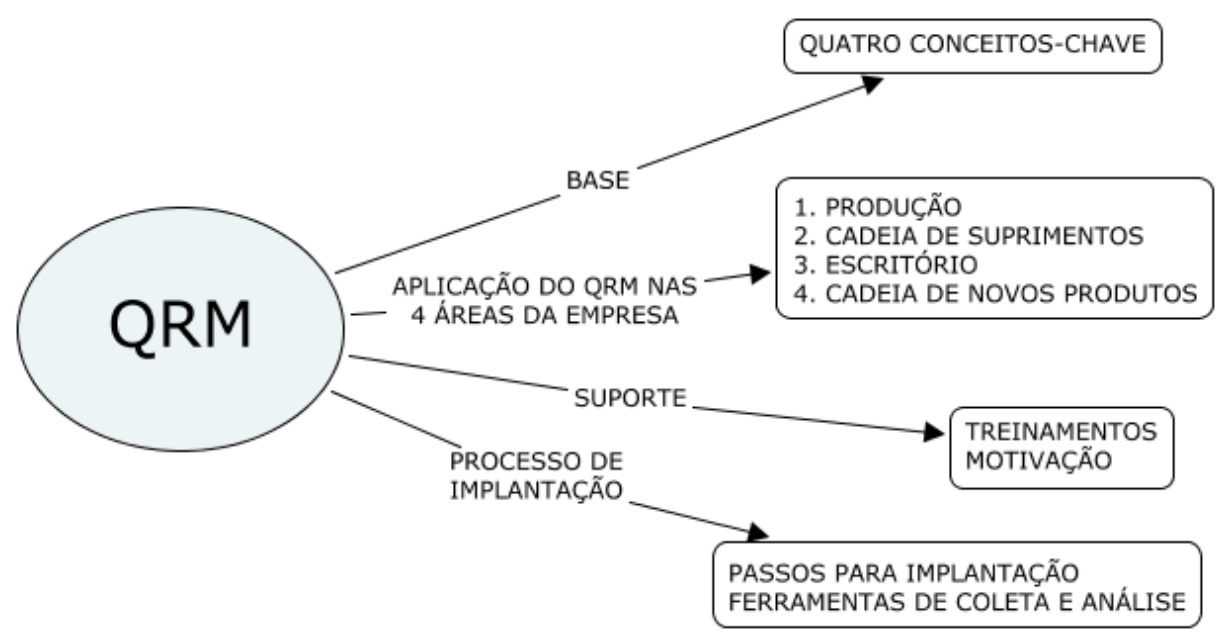

Fonte: Adaptado de Suri (2010)

Para a execução da estratégia do QRM, é proposto que a redução do lead time seja realizada por meio da implementação de um projeto que segue uma metodologia composta por quatro fases: coleta e análise de dados; identificação das causas do longo lead time; propostas de melhorias baseadas nos princípios e ferramentas do QRM e análise dos resultados esperados (SURI, 1998). A prática da previsão da necessidade de produtos e serviço ainda continua dependente do julgamento humano, entretanto, a crescente variedade de abordagens gerenciais e de modelos quantitativos, como as estratégias do QRM, tem sido frequentemente proposta como meios eficazes para diminuir o lead time de produção e reduzir incerteza da demanda (SEIFERT et al., 2015).

Para a coleta e análise de dados, O QRM utiliza uma série de técnicas e métodos que são empregados em diversos trabalhos da engenharia de produção, tais como as ferramentas de qualidade, simulação discreta, dentre outros. Outro método proposto por Suri (1998) para ser utilizado dentro do escopo da abordagem do QRM é o MCT - Manufacturing Critical-path Time, um instrumento que permite identificar todas as fases do processo e os pontos onde o lead time pode ser melhorado, através da visualização do seu caminho crítico, desde a emissão do pedido até que a primeira peça seja entregue ao cliente que a demandou (GODINHO FILHO; HAYASHI; RUFO, 2013).

O MCT é um valor representativo do tempo real, levando em consideração interações típicas que ocorrem no sistema produtivo, que são comuns em todas as empresas. Essa quantidade de tempo é medida em dias do calendário ( 24 horas), a partir do momento em que um cliente cria uma ordem, até a primeira entrega dessa ordem ao cliente final (ERICKSEN; STOFLET; SURI, 2007).

O propósito da ferramenta MCT é manter os esforços de coleta de dados em um nível muito mais simples para proporcionar uma razoável estimativa tornando possível identificar as maiores oportunidades de melhorias (obter retornos sobre as 
principais causas de longos prazos de entrega e os resíduos do sistema). Assim, duas medidas de tempo são encontradas, possibilitando comparação entre eles, que são o tempo blank (que não agrega valor) e o tempo touch (que agrega valor).

A quantidade de tempo que não agrega valor tende a ser muito elevada na maioria dos casos, geralmente administradores e empregados são surpreendidos e motivados a tomar uma ação corretiva, utilizando os métodos do QRM. Assim, não é necessário que este valor seja extremamente preciso, desde que demonstre claramente a magnitude envolvida.

A Figura 2 apresenta um exemplo de MCT. É perceptível que o tempo que agrega valor (em amarelo na figura) é muito menor que o tempo que não agrega valor (em vermelho na figura). Existe a possibilidade de representar as atividades que não agregam valor e não são necessárias e as atividades que não agregam valor e são necessárias. Assim, o MCT pode ressaltar visualmente os desperdícios e as oportunidades para melhoria e providenciar uma linguagem comum para fazer comparações (ERICKSEN; STOFLET; SURI, 2007).

Figura 2 - Exemplo de MCT

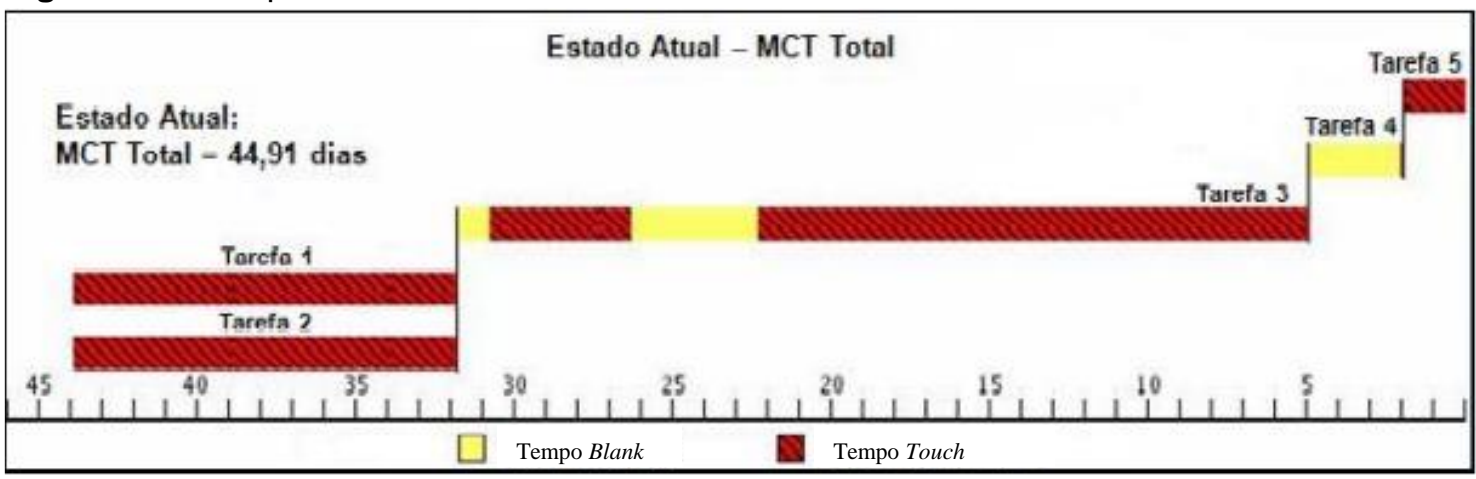

Fonte: Adaptado de Ericksen; Stoflet; Suri (2008)

Suri (1998), ao aplicar o MCT na manufatura, indica que quatro componentes estejam presentes: MCT para os insumos; MCT para as operações de planejamento e manufatura; MCT para o estoque e MCT para a logística. Nessa última, se vê que é possível usar o MCT para reduzir tempos de movimentação associados à logística, como os tempos de transporte, distribuição e entrega.

\section{MÉTODO DE PESQUISA}

O método aplicado para o desenvolvimento desta pesquisa utilizou uma abordagem explicativa qualitativa através do objeto do estudo de caso. O estudo de caso consiste em métodos de análises que podem ser aplicados em trabalhos que promovam sequência de etapas gerenciais (NEVES; CONEJERO, 2012). Os métodos qualitativos devem empregar uma abordagem diferente da investigação acadêmica (CRESWELL, 2010). De Sordi (2013) apresenta que a investigação 
qualitativa emprega técnicas interpretativas para a análise do fenômeno. Sobre o objeto de análise, a empresa escolhida pertence ao setor terciário da economia, o comércio de flores, e tem sede na cidade de Campinas/SP.

Os procedimentos utilizados para desenvolver a pesquisa foram baseados na proposta de Suri (1998) para a realização de um projeto QRM, que são (i) coleta e análise dos dados; (ii) identificação das causas do longo lead time; (iii) proposta de melhorias; e (iv) simulação dos resultados esperados.

Para auxiliar na fase de coleta e análise de dados foi aplicado um roteiro préelaborado com os dados primários da cadeia logística, envolvendo o fornecedor e a rede varejista de flores com a análise de cada tempo de todo o lead time do processo logístico, desde o fornecedor até o cliente final. A Figura 3 ilustra os procedimentos seguidos no decorrer da pesquisa.

Figura 3 - Procedimentos da pesquisa

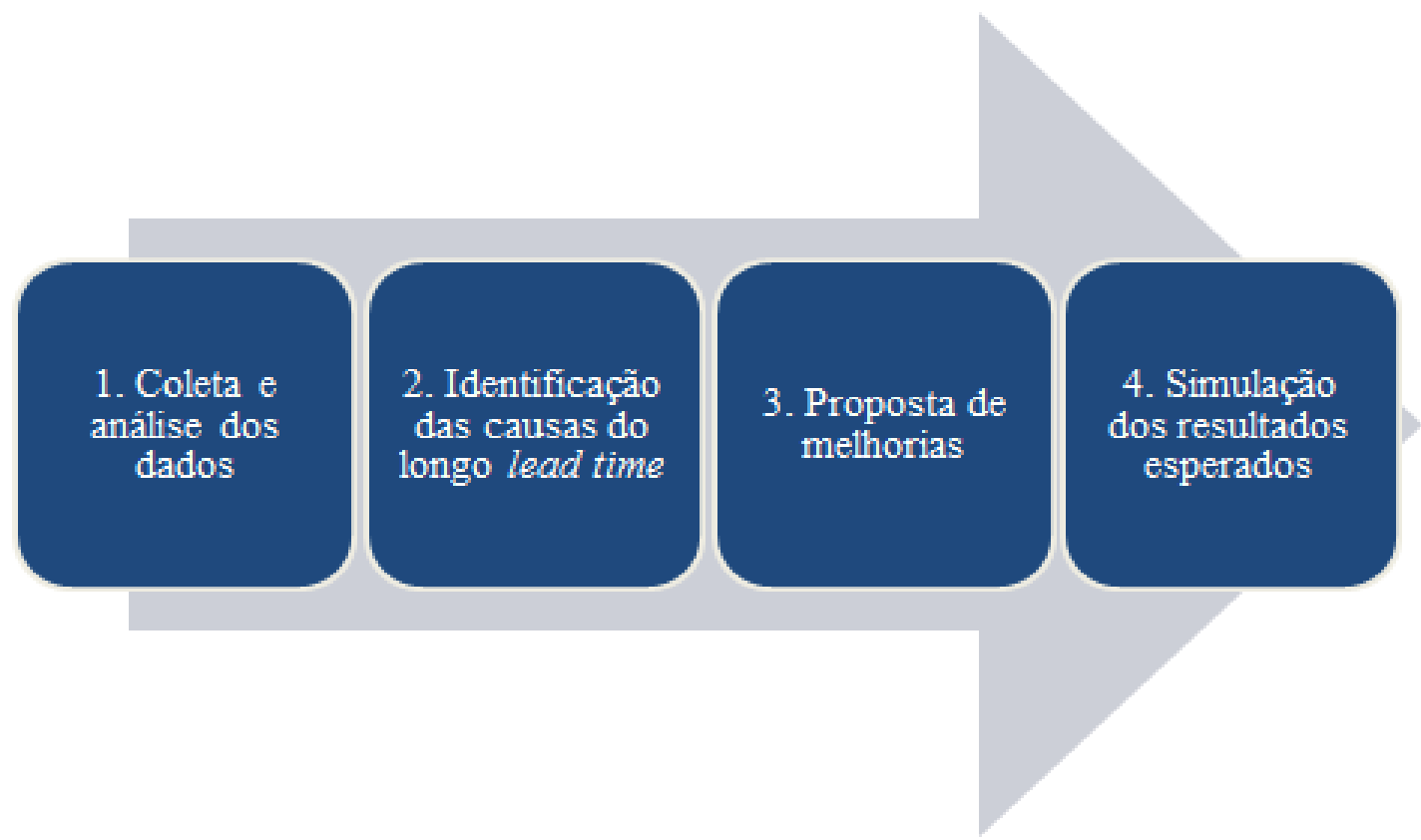

Fonte: Elaboração própria com base em Suri (1998)

A primeira etapa da pesquisa contemplou o levantamento inicial dos processos operacionais existentes na rede de flores. Essa coleta de dados e informações foi obtida por meio de entrevistas com a proprietária da rede e alguns envolvidos mais próximos. Esse primeiro levantamento deu origem a um plano de prioridades de investigação, que definiu os locais para serem realizadas as visitas para ter informações mais completas. Assim, realizaram-se visitas ao principal fornecedor, o Veiling Holambra, para entendimento do processo como um todo, e posteriormente nas lojas próprias da rede sediadas em Campinas.

$\mathrm{Na}$ segunda etapa, de identificação de causas do longo lead time, algumas ferramentas foram utilizadas com o objetivo de identificar, priorizar e analisar o 
problema, como o Fluxograma Padrão e o Mapa de Fluxo de Valor, enquanto outras foram utilizadas para identificar efetivamente as causas, como o Diagrama de Ishikawa e Brainstorming, e outra ainda para analisar mais profundamente a causa e sugerir propostas de melhoria, como o MCT. É essa última o foco ferramental dessa pesquisa, que fornecerá dados reais e completos a cerca dos tempos utilizados atualmente no processo.

$\mathrm{Na}$ etapa 3, de proposta de melhorias, novas ações foram sugeridas na pesquisa e expostas aos envolvidos diretamente nos processos, a fim de identificar inicialmente a viabilidade da mudança, usando-se do know-how dos atores principais. Foram realizados alguns questionamentos a respeito das mudanças sugeridas, como por exemplo, as condições de compra das flores, como o período, a frequência e o fornecedor, e também sobre a distribuição das flores, como o meio de transporte, os prazos, e os custos.

E por último, na etapa 4, realizou-se uma simulação dos resultados esperados nas propostas de melhorias, e para isso também foi utilizada a ferramenta MCT, desenhando os processos e seus novos tempos de acordo com as mudanças sugeridas na pesquisa.

Os resultados efetivos de cada etapa proposta aqui no método de pesquisa podem ser acompanhados diretamente nos tópicos seguintes.

\section{O ESTUDO DE CASO}

\subsection{O processo estudado}

A rede varejista de flores, a qual se destina a análise nesta pesquisa, está no mercado desde 1985 e nasceu em Campinas em uma loja do bairro do Cambuí, que está em funcionamento até hoje. Sua idealizadora iniciou o pequeno negócio de forma artesanal sem praticamente nenhuma experiência no ramo. A partir de 1995 abriu sua segunda loja também na cidade de Campinas.

Em 2010, a empresa iniciou um projeto de expansão através do sistema de franchising e sua primeira loja franqueada foi em Salvador/BA, seguindo com a instalação de outras duas franquias nas cidades de Vila Velha/ES e Rio de Janeiro/RJ. Atualmente a rede possui duas lojas próprias na cidade de Campinas e três franquias.

A logística de distribuição foi a primeira limitação que a franquia enfrentou na intenção de transportar as flores de Campinas para as outras cidades. Assim, foi necessário esquematizar um plano de distribuição específico para cada loja, descrito na Figura 4. As entregas das flores partem algumas vezes diretamente de Holambra, onde a maioria das flores é comprada, e em outras vezes de Campinas, onde a compra ocorre na CEASA - Central Estadual de Abastecimento Sociedade Anônima. Atualmente, a compra das flores acontece na Cooperativa Veiling Holambra e na 
CEASA de Campinas. A rede de distribuição para as lojas dos outros estados acontece por transporte aéreo e/ou terrestre, dependendo da distância e viabilidade econômica.

Figura 4 - Plano de distribuição de flores

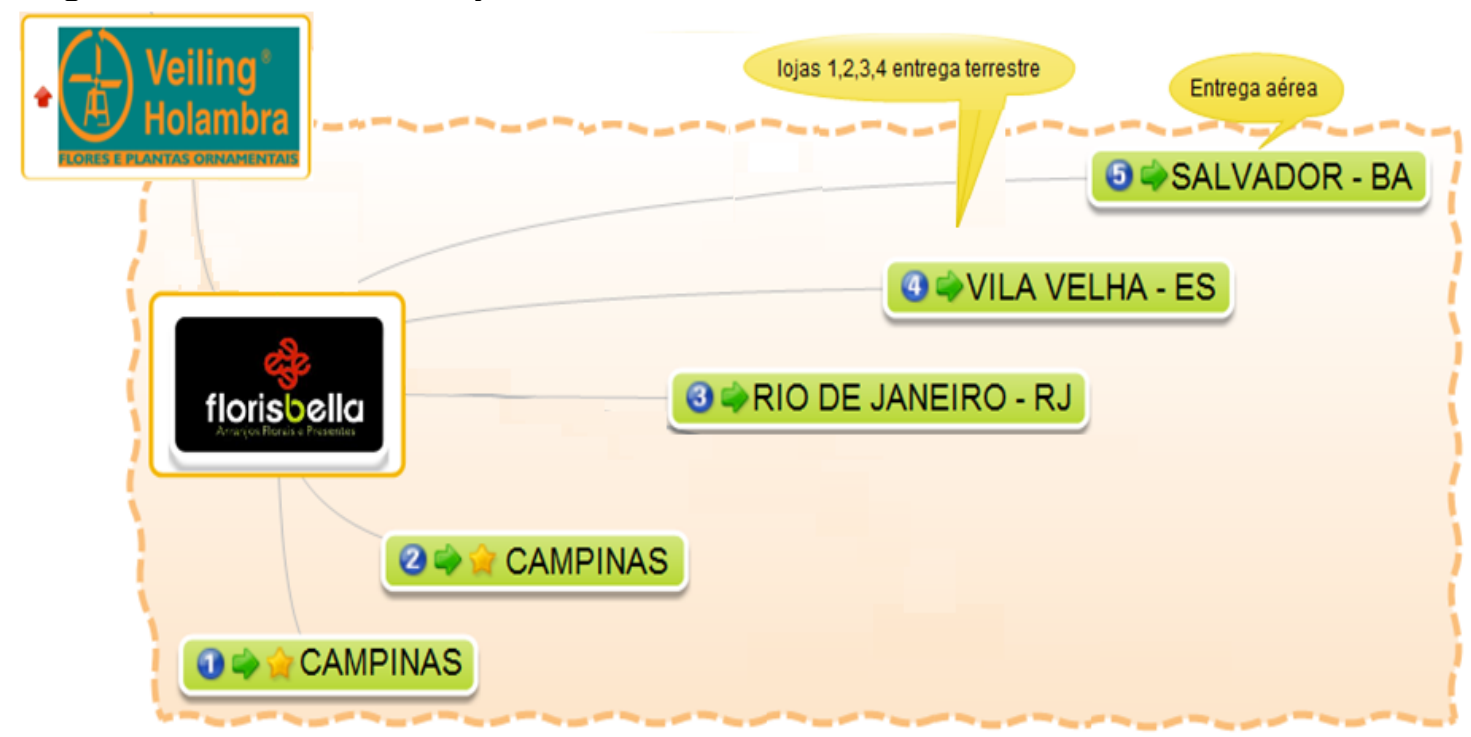

Fonte: Elaboração própria (2015)

As atividades relacionadas a todo o processo da compra e distribuição de flores foram detalhadas em um fluxograma padrão, conforme segue na Figura 5, e foram aprofundadas individualmente e com mais particularidades em um mapa de fluxo de valor, presente na Figura 6. Essas foram as ferramentas utilizadas para compreender o processo e identificar e priorizar as causas do alto lead time. 
Figura 5 - Fluxograma da rede de flores

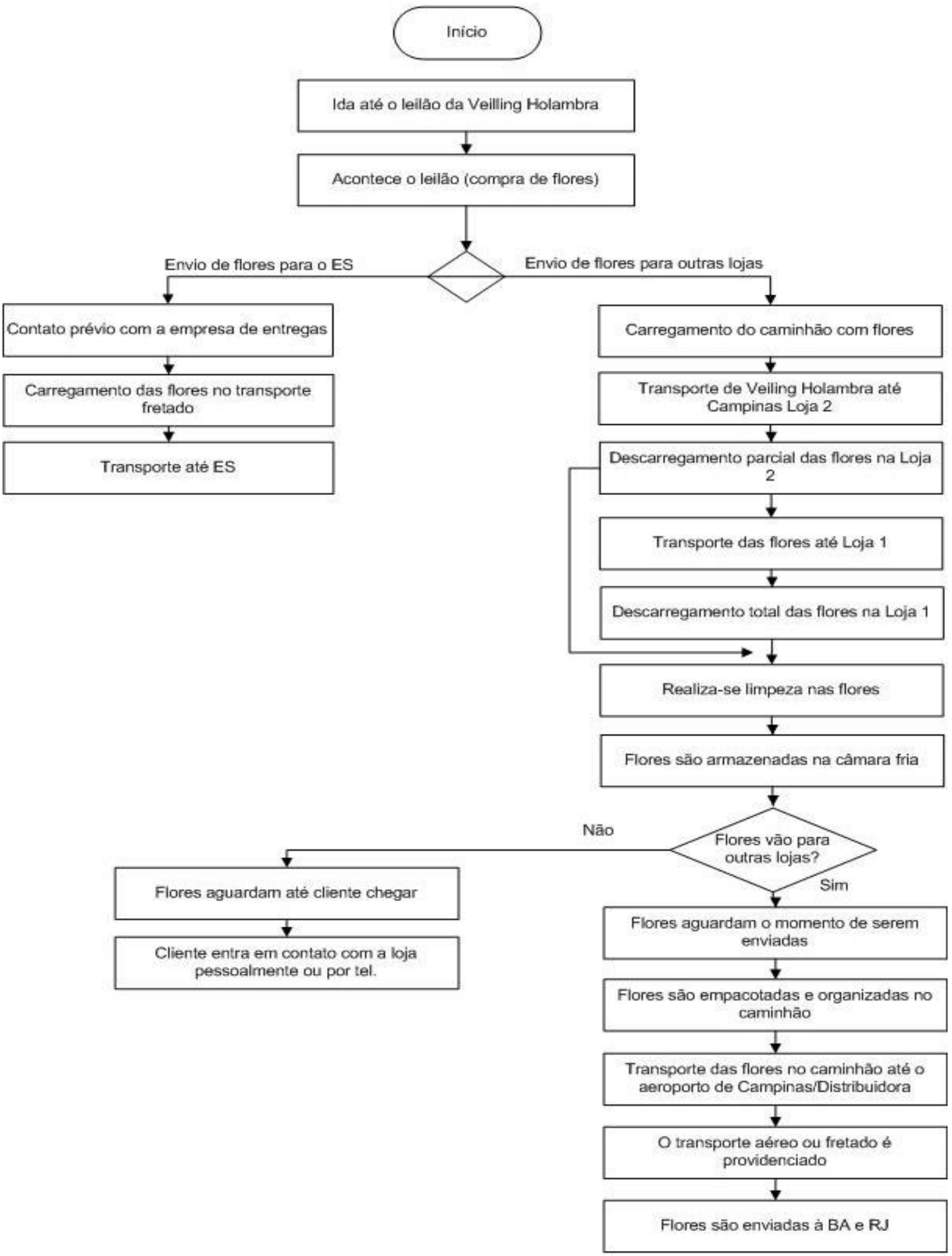

Fim

Fonte: Elaboração própria (2015)

Revista Produção Online, Florianópolis, SC, v. 16, n. 4, p. 1237-1261, out./dez. 2016. 
Figura 6 - Mapa de fluxo de valor da rede de flores

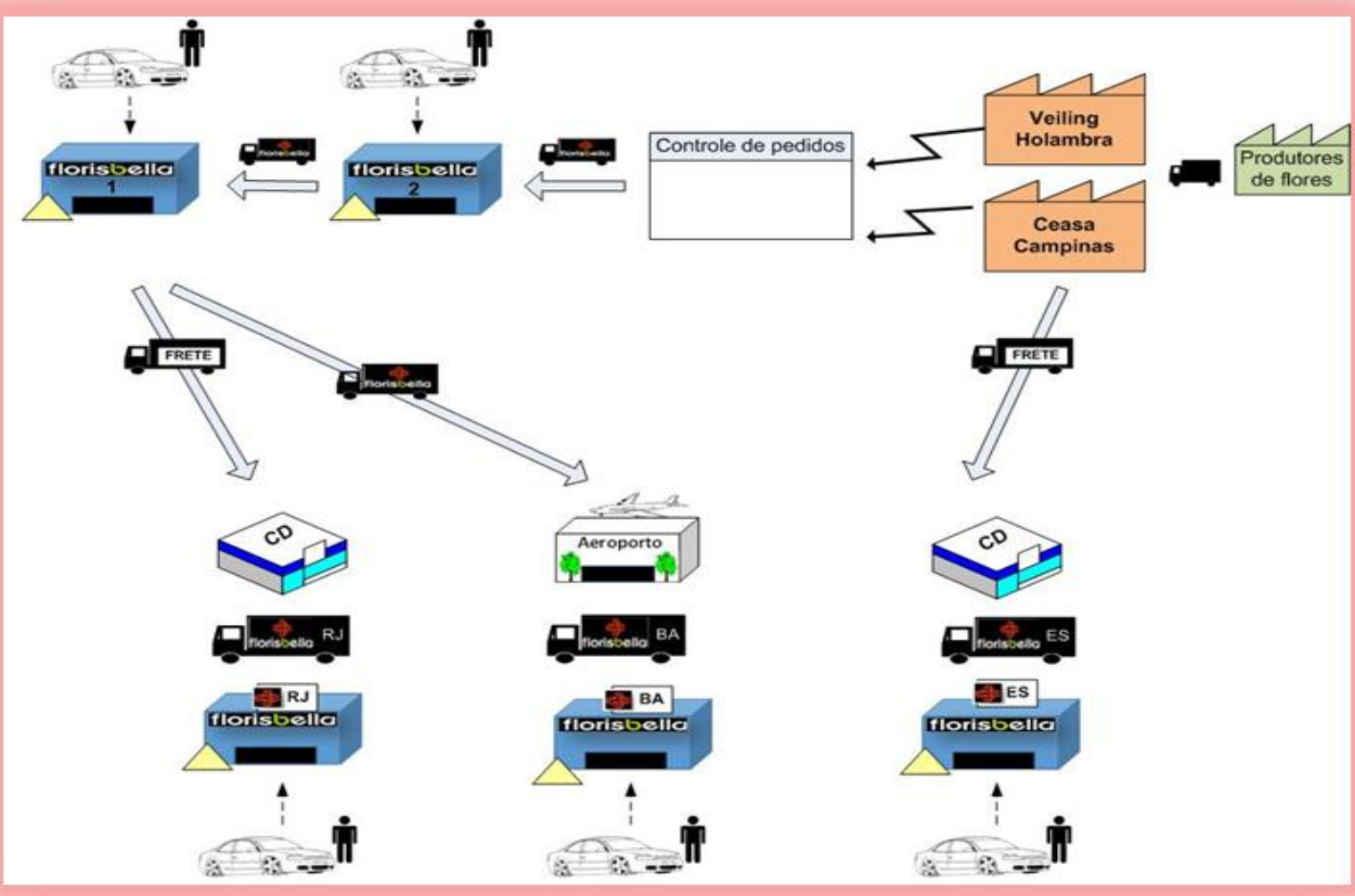

Fonte: Elaboração própria (2015)

No mapa de fluxo de valor foi possível identificar e analisar detalhadamente toda a movimentação da cadeia logística da rede de flores. No início do fluxo há o produtor das flores, que após a colheita entrega seus produtos na central de distribuição que pode ser o Veiling Holambra ou a CEASA. A proprietária da franquia vai até esses distribuidores para comprar flores para toda a sua rede (cinco lojas), diante de um controle de pedidos demandado. Na situação das lojas 1 e 2, que são próprias e localizadas em Campinas, após a compra, o caminhão segue com as flores para a loja 2 onde é realizada uma entrega parcial e posteriormente, deslocase para a loja 1, onde permanecerá o restante das flores. A definição das paradas, primeiro na loja 2 e depois na loja 1 é devida à sequência de posicionamento na rota do caminho.

A logística de distribuição para a loja do Rio de Janeiro é por meio de um caminhão fretado, seguindo da loja 1 (principal em Campinas), onde fica o "estoque" das flores. Para o franqueado da Bahia, as flores são movimentadas também da loja 1 através de transporte próprio até o Aeroporto de Campinas e no caso do franqueado de Espirito Santo, o transporte é em caminhão fretado, porém saindo diretamente dos fornecedores iniciais, ou seja o Veiling Holambra e/ou CEASA. Ao chegarem aos seus destinos, os representantes de cada franquia encarregam-se do transporte entre depósito central (local onde a transportadora entrega, podendo ser 
um $C D$ da própria transportadora) ou aeroporto para a loja varejista, que é o destino final das flores, antes de chegarem aos consumidores finais.

A identificação efetiva das causas dos longos lead time foi possibilitada pelo uso das ferramentas Diagrama de Ishikawa e Brainstorming. Com o Diagrama de Ishikawa, na Figura 7, foi possível rever as possíveis causas para os quesitos de método, medida, mão de obra e material, todos para identificar motivos para o longo lead time. Esse diagrama, também conhecido como diagrama causa e efeito, é uma das ferramentas sugeridas por Suri (1998) para analisar as causas dos problemas de alto lead time, sendo assim escolhida para apresentar essa relação e os pontos em que podem ocorrer melhorias.

Na própria identificação das causas iniciais, com o Diagrama de Ishikawa foi utilizada a ferramenta de Brainstorming com a equipe para levantar os pontos relevantes. Dentre as possíveis causas listadas, o tempo de transporte, juntamente com o roteiro logístico, foram os principais problemas para desenvolver os tempos para o MCT, visto que cada uma das lojas possui um roteiro logístico diferente, assim como uma combinação diferente de tipos de transporte utilizado.

Figura 7 - Diagrama de Ishikawa

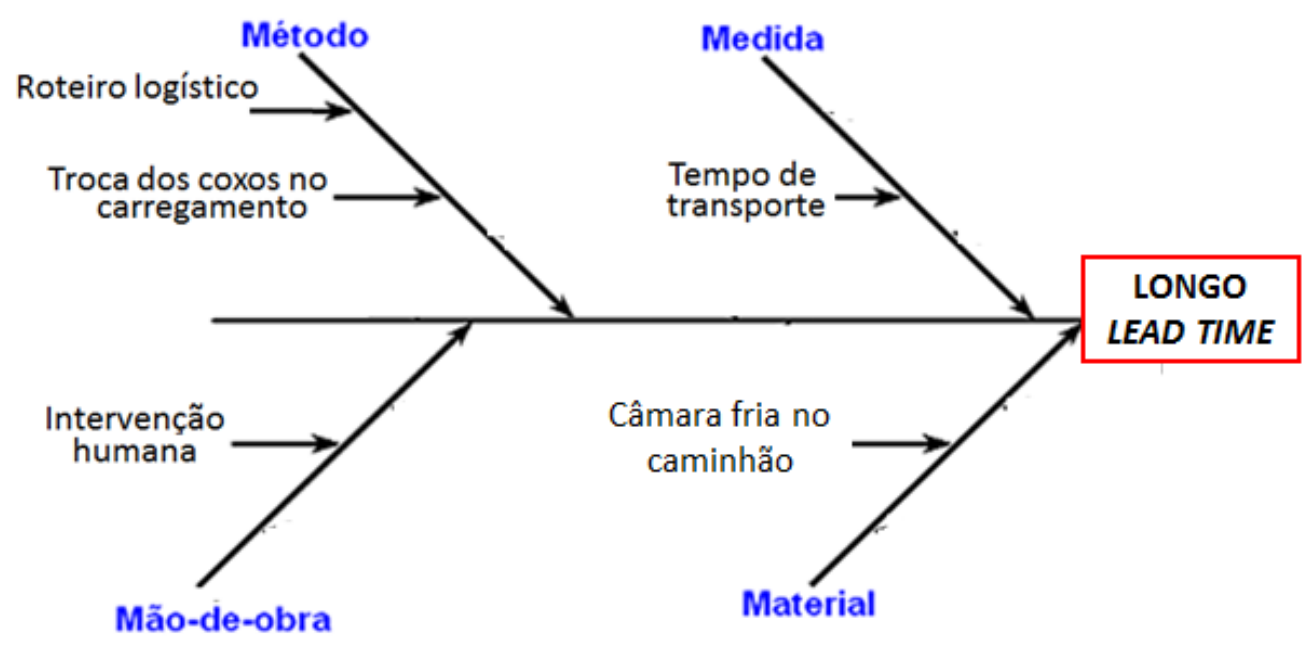

Fonte: Elaboração própria (2015)

\subsection{Propostas de melhoria}

Com as possíveis causas listadas no Diagrama de Ishikawa, tempo de transporte e roteiro logístico, necessitou-se analisar de forma mais detalhada os longos lead times, e para isso foram elaborados os MCT's iniciais e propostos. A ferramenta MCT, que expõe em forma de gráfico os tempos blank e touch, permitiu comparar os lead time atualmente utilizado pela empresa e o proposto pelo estudo. Assim, será possível conhecer o tempo gasto para que o produto percorra o caminho necessário desde a compra no distribuidor até a entrega final do produto ao cliente, e também uma proposta de ações que melhorem esse tempo. 
Por meio do MCT observou-se a quantidade de tempo efetivamente produtivo e os improdutivos incorporados ao processo. Os espaços preenchidos em vermelho representaram os tempos gastos para a realização de um processo e os espaços em cinza são referentes às atividades que não agregaram valor ao produto, tais como esperas, transportes desnecessários, estoques, entre outros.

Segundo Ericksen; Stoflet; Suri (2007), a fim de reduzir o lead time, primeiro deve ser realizado o MCT atual e posteriormente um novo MCT com as mudanças sugeridas para comparar as duas situações. Os MCT's (atual e proposto) são apresentados de forma simultânea a fim de que o leitor possa comparar as sugestões de melhorias. Os gráficos de MCT para a loja 1 (loja própria situada em Campinas) são apresentados nas Figuras $8 \mathrm{a}$ e $8 \mathrm{~b}$.

Figura $8 \mathbf{a}-\mathrm{MCT}$ original da loja Campinas 1

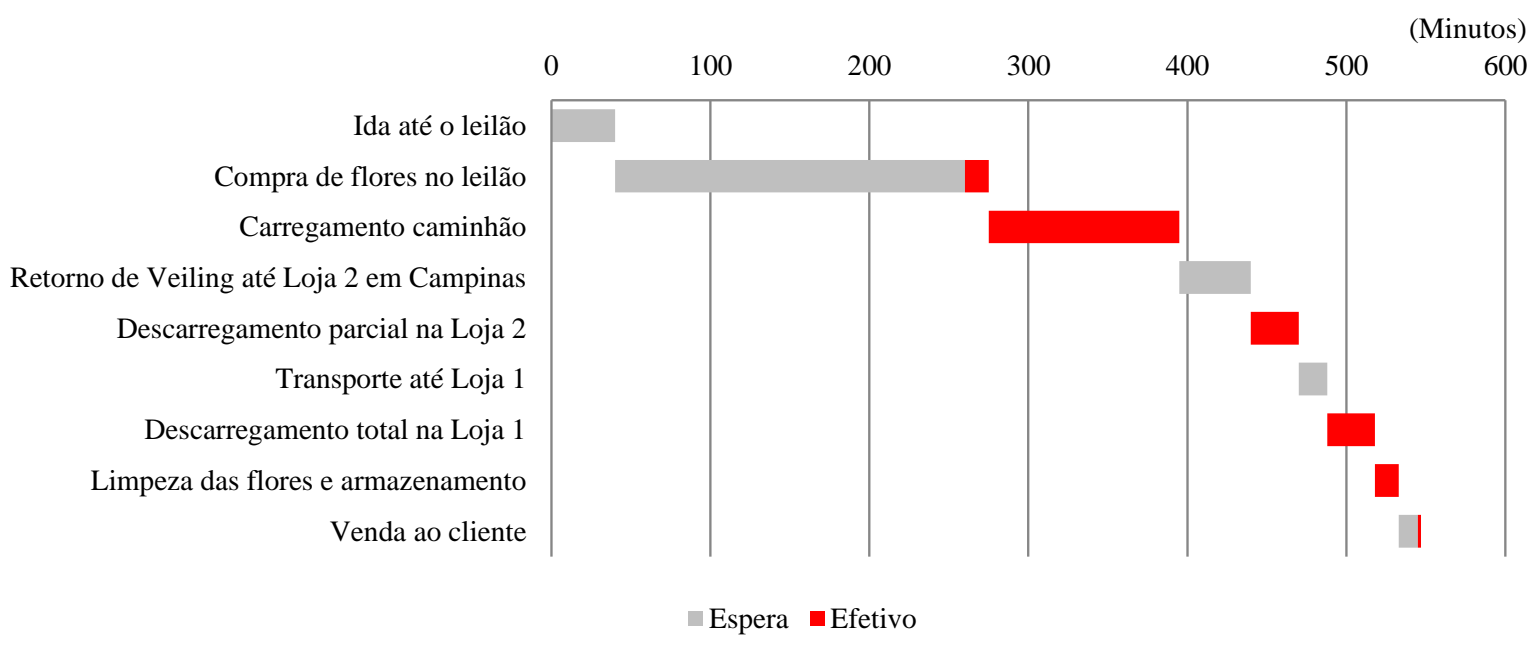

Fonte: Elaboração própria (2015)

Figura $\mathbf{8 b}$ - Novo MCT para a loja Campinas 1

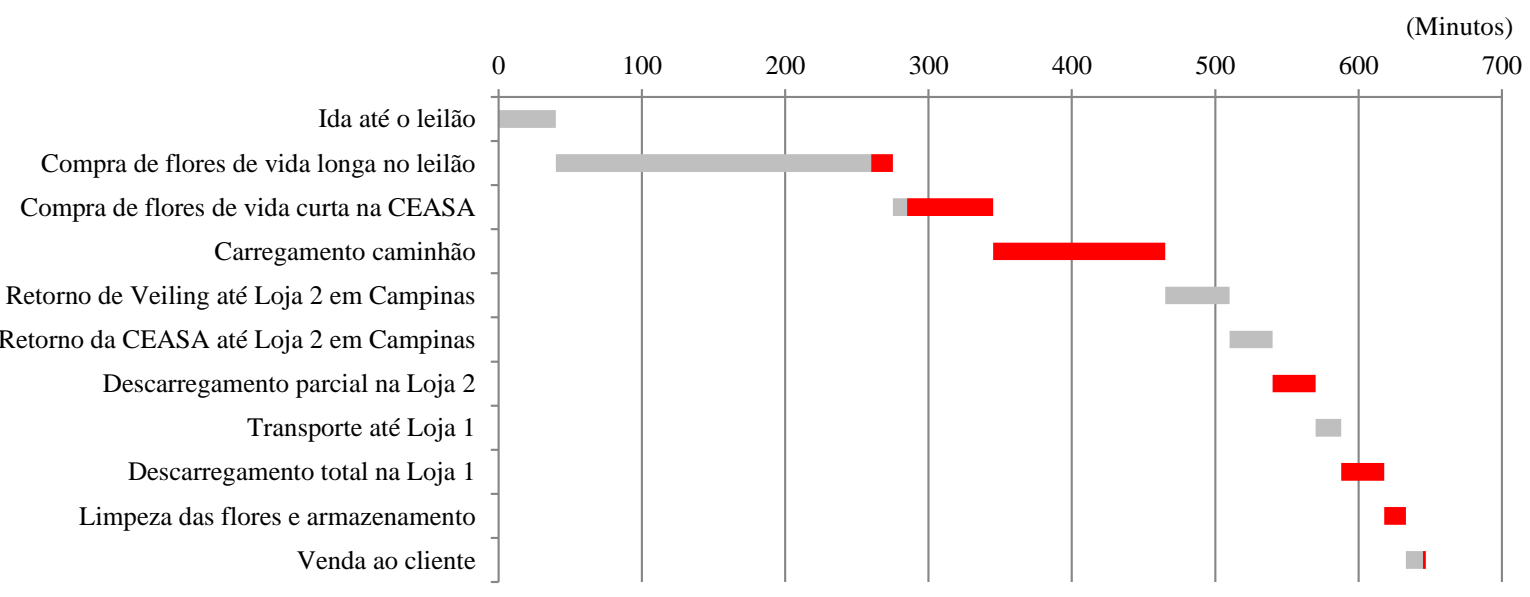

Fonte: Elaboração própria (2015) 
Na Figura 8a, loja 1, observou-se que os maiores espaços em cinza estão localizados nas duas primeiras atividades do processo, que são a ida até o leilão e a compra das flores no leilão na cidade de Holambra, representando $50,3 \%$ do lead time, sendo que o maior tempo efetivo do processo representa $21,9 \%$. Outro ponto que merece destaque é o tempo de retorno até a cidade de Campinas, correspondendo a $17 \%$.

Para reduzir o tempo de compra no leilão de flores em Holambra, anteriormente realizado semanalmente para todos os tipos de flores, verificou-se a possibilidade de analisar o tempo de vida útil de cada grupo de flores, verificando a viabilidade de estratificar a compra. A proposta foi de realizar a compra das flores de vida útil curta (7 a 10 dias) em outros mercados atacadistas, como Cooperativas e CEASAs das cidades de Campinas, Vila Velha, Salvador e Rio de Janeiro, sem perder a qualidade da matéria-prima, fator este primordial neste ramo de atividade. Já para as flores de vida longa ( 3 meses), a sugestão foi realizar as compras apenas duas vezes por mês.

As Figuras 9a e 9b apresentam os MCT's atual e proposto, respectivamente, para a loja 2 (loja própria também em Campinas). Na Figura 9a, do MCT original, verificou-se que a loja 2 apresentou os mesmos problemas de tempos da loja 1 , sendo que a ida até o leilão e a compra das flores no leilão na cidade de Holambra representam $55,1 \%$ do lead time, o retorno até Campinas representa $9 \%$ e o maior tempo efetivo do processo que é o carregamento do caminhão representa $24 \%$. Dados similares foram observados por Soulé et al. (2016) em sua pesquisa de estudo de caso em pequena empresa familiar de produtos termoelétricos. A estratificação das compras proposta também reduzirá esses tempos.

Figura 9a-MCT original da loja Campinas 2

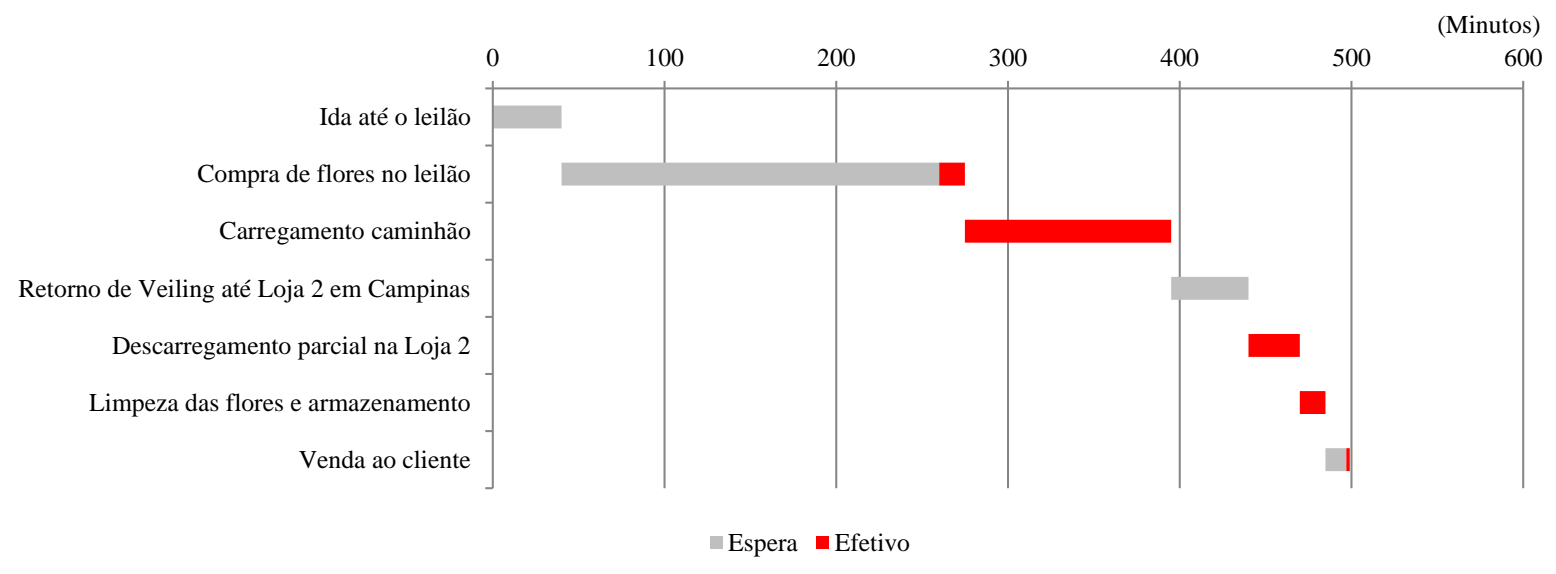

Fonte: Elaboração própria (2015) 
Figura 9b - Novo MCT para a loja Campinas 2

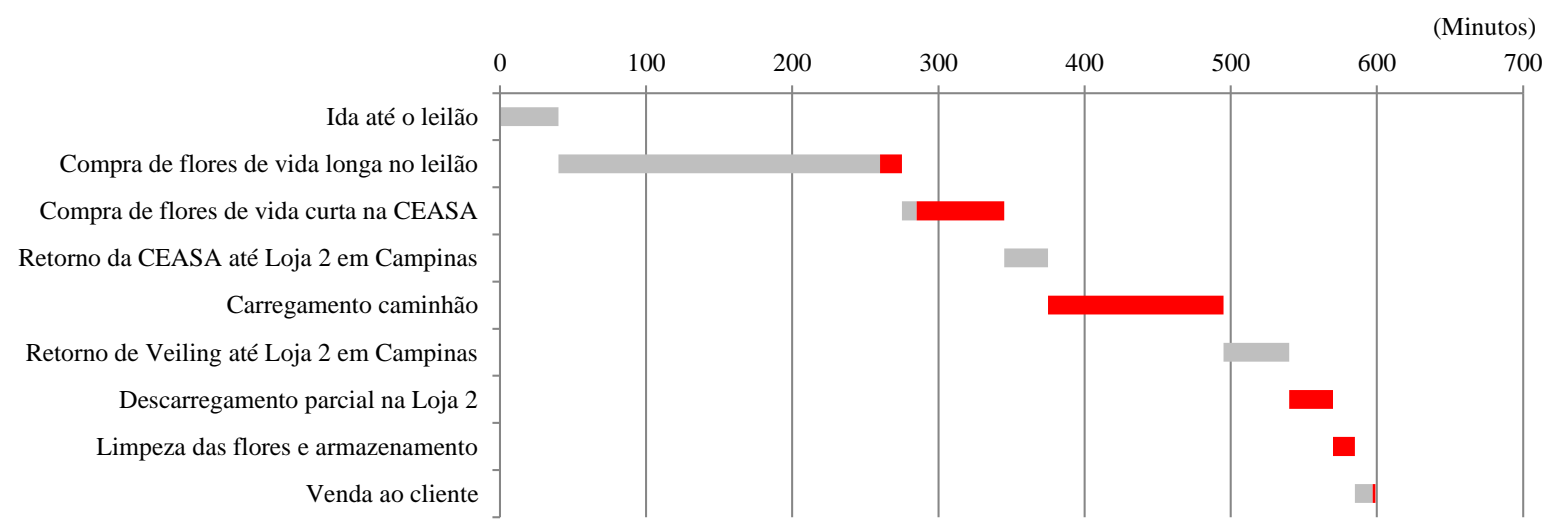

Fonte: Elaboração própria (2015)

O mesmo procedimento de desenvolvimento do MCT também foi realizado nas franquias localizadas nos estados de Espirito Santo, Bahia e Rio de Janeiro. Nas Figuras 10a e 10b estão os MCT's da loja de Vila Velha/ES. No MCT atual (Figura 10a) observou-se que os maiores tempos em espera estão localizados nas etapas de transporte de Campinas até a loja em Vila Velha $(68,9 \%)$ e o tempo aguardando a retirada das flores (14\%).

Com a mudança nos locais e períodos de compras, também foi possível reduzir-se em $50 \%$ do tempo, a atividade de espera de início de carregamento do caminhão para o transporte até a loja do Espirito Santo.

Figura 10a - MCT original da loja Vila Velha/ES

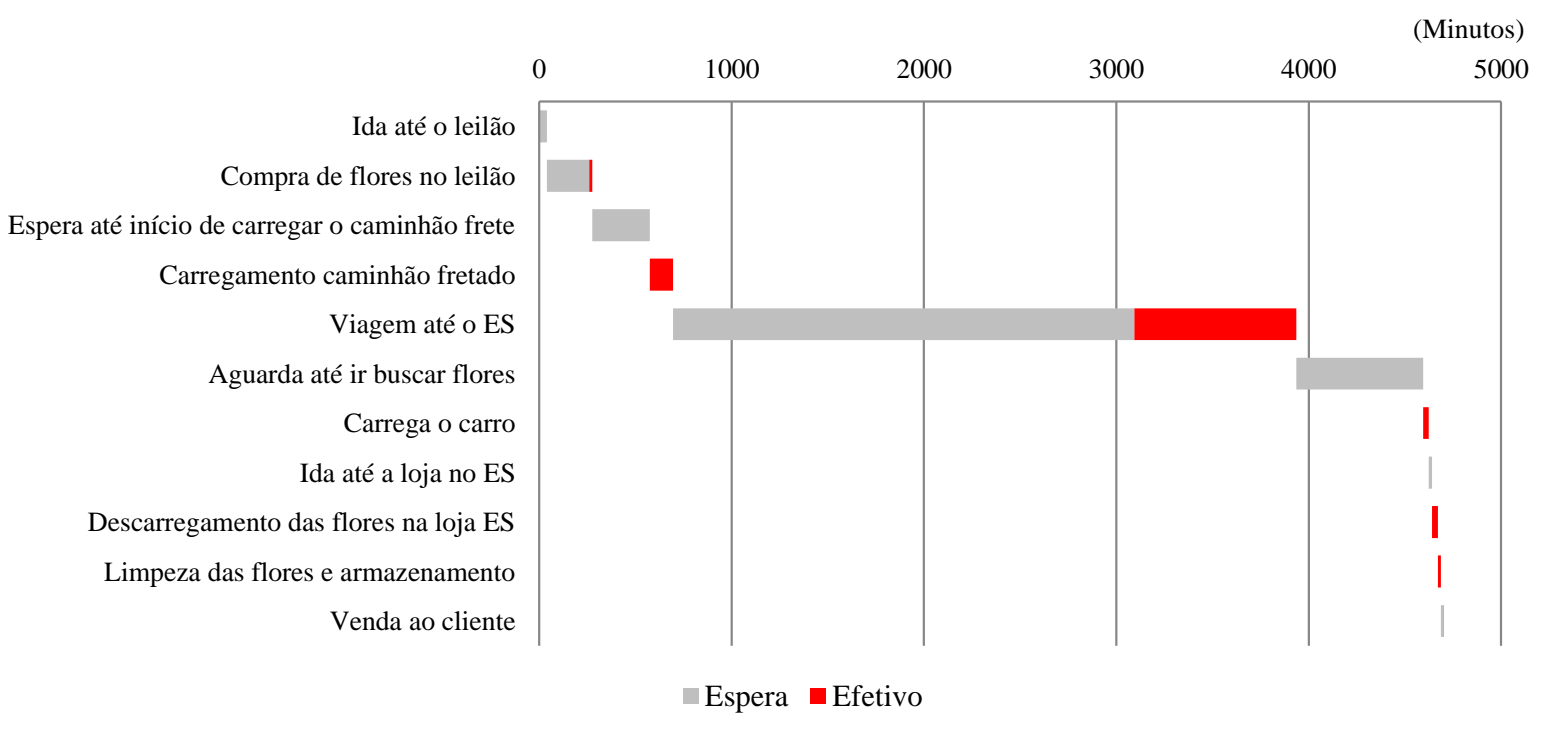

Fonte: Elaboração própria (2015) 
Figura 10b - Novo MCT para a loja Vila Velha/ES

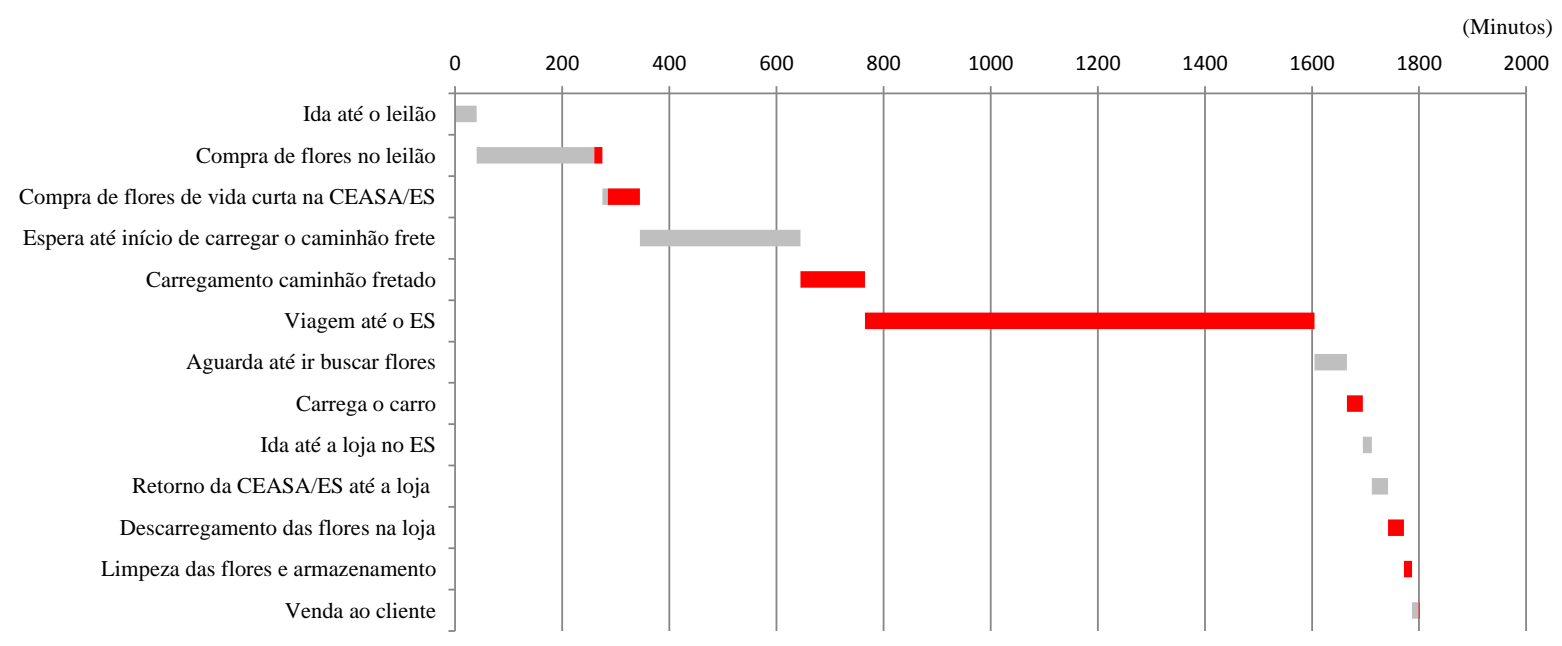

Fonte: Elaboração própria (2015)

As Figuras 11a e 11b apresentam os MCT's da loja de Salvador/BA, onde os maiores tempos improdutivos estão relacionados à compra de flores no leilão em Holambra (14\%) e a espera da retirada das flores no aeroporto de Salvador (54\%). Nessa loja, a ação proposta foi a roteirização do trajeto e horário de chegada às cidades em horário comercial e de preferência no turno manhã do dia, com definição de um melhor horário de saída do transporte aéreo.

Figura 11a - MCT original da loja Salvador/BA

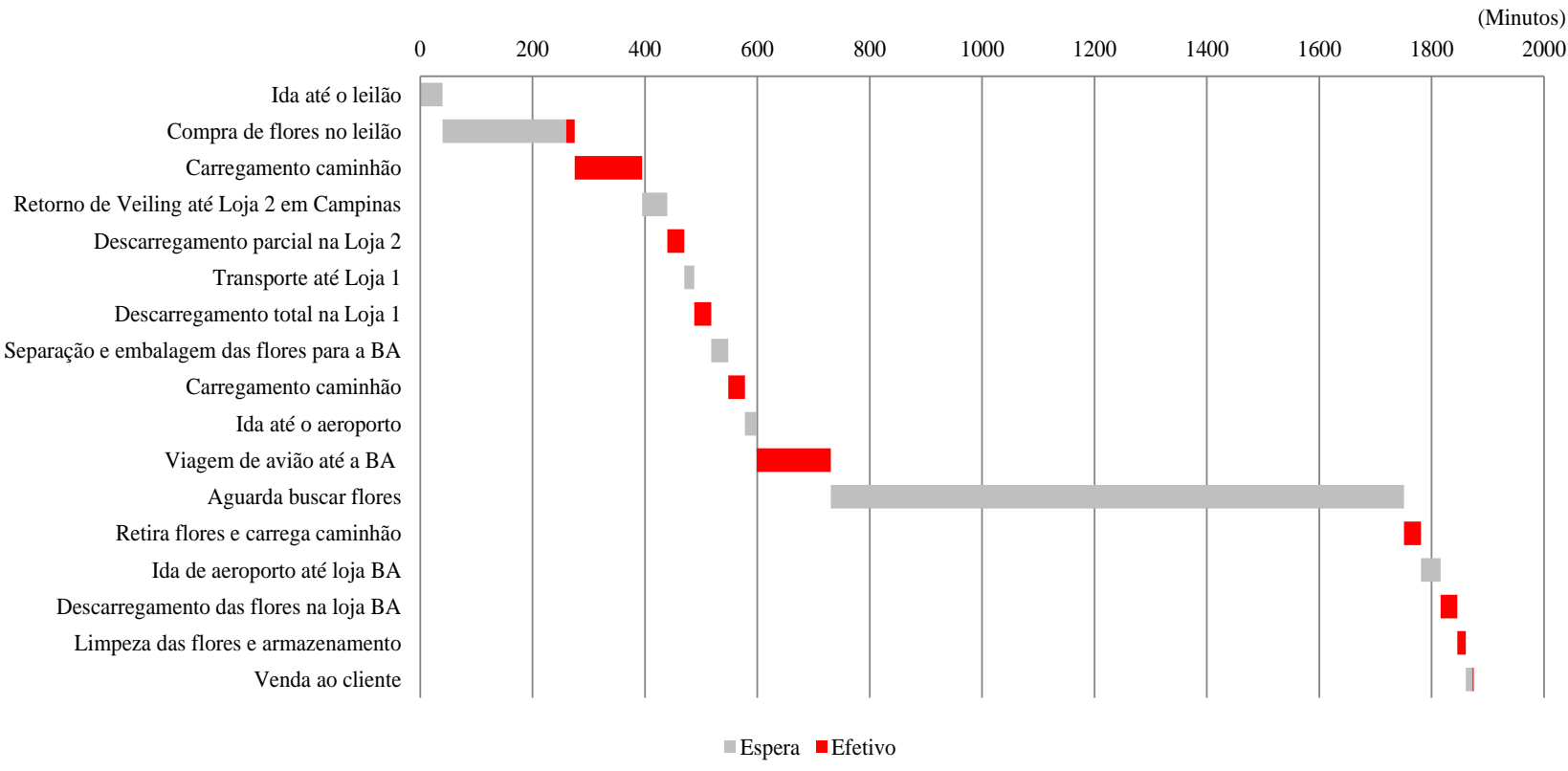

Fonte: Elaboração própria (2015) 
Figura 11b - Novo MCT para a loja Salvador/BA

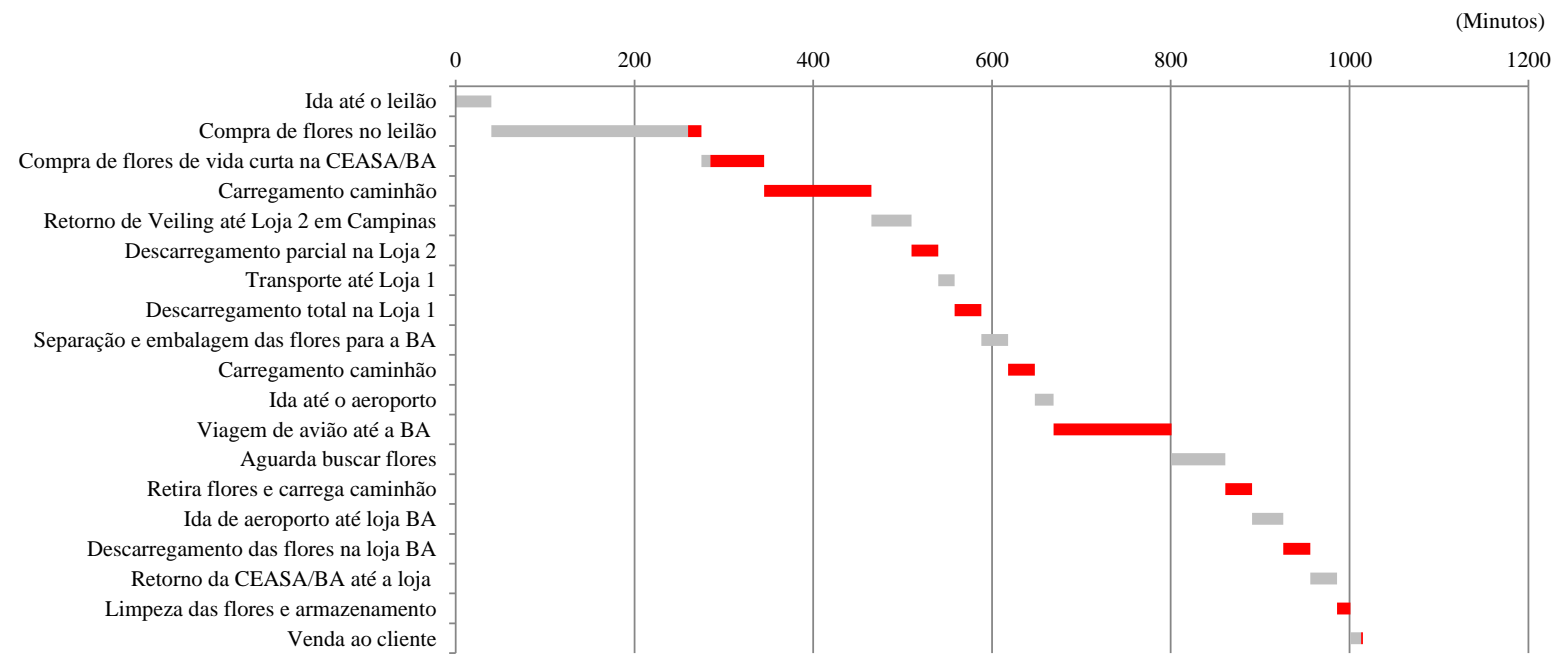

Fonte: Elaboração própria (2015)

Quando analisada a loja do Rio de Janeiro/RJ (Figura 12a e 12b) foi observado tempos ociosos relacionados às atividades de aguardar o transporte terrestre até a cidade do Rio de Janeiro (54\%) e o tempo aguardando a retirada das flores (13\%). Com a ação proposta de menor quantidade de flores adquiridas em Holambra planejou-se melhor a parceria com a empresa de transporte e eliminou a grande espera para ir até o Rio de Janeiro.

Figura 12a - MCT original da loja Rio de Janeiro/RJ

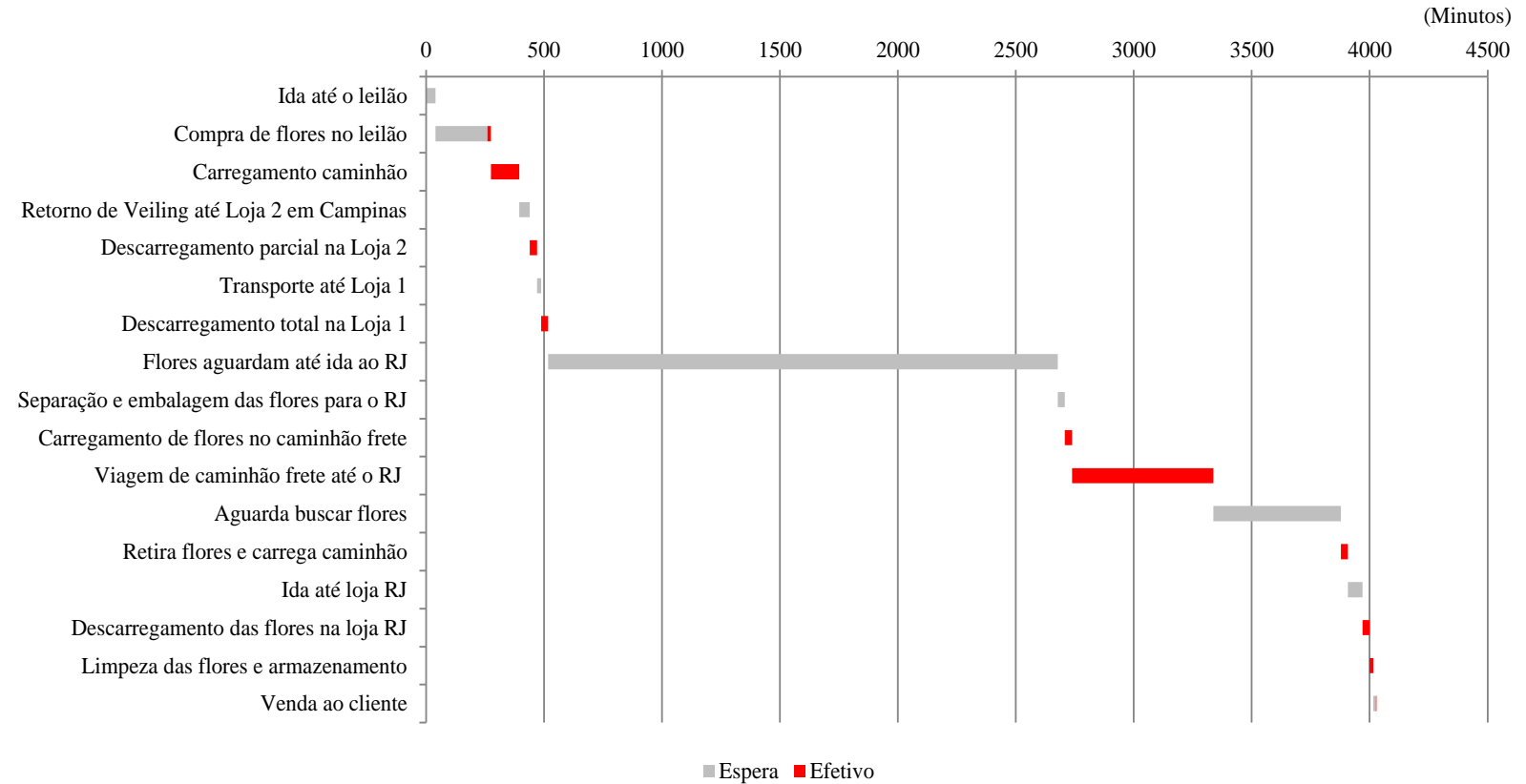

Fonte: Elaboração própria (2015)

Revista Produção Online, Florianópolis, SC, v. 16, n. 4, p. 1237-1261, out./dez. 2016. 
Figura $12 b$ - Novo MCT para a loja Rio de Janeiro/RJ

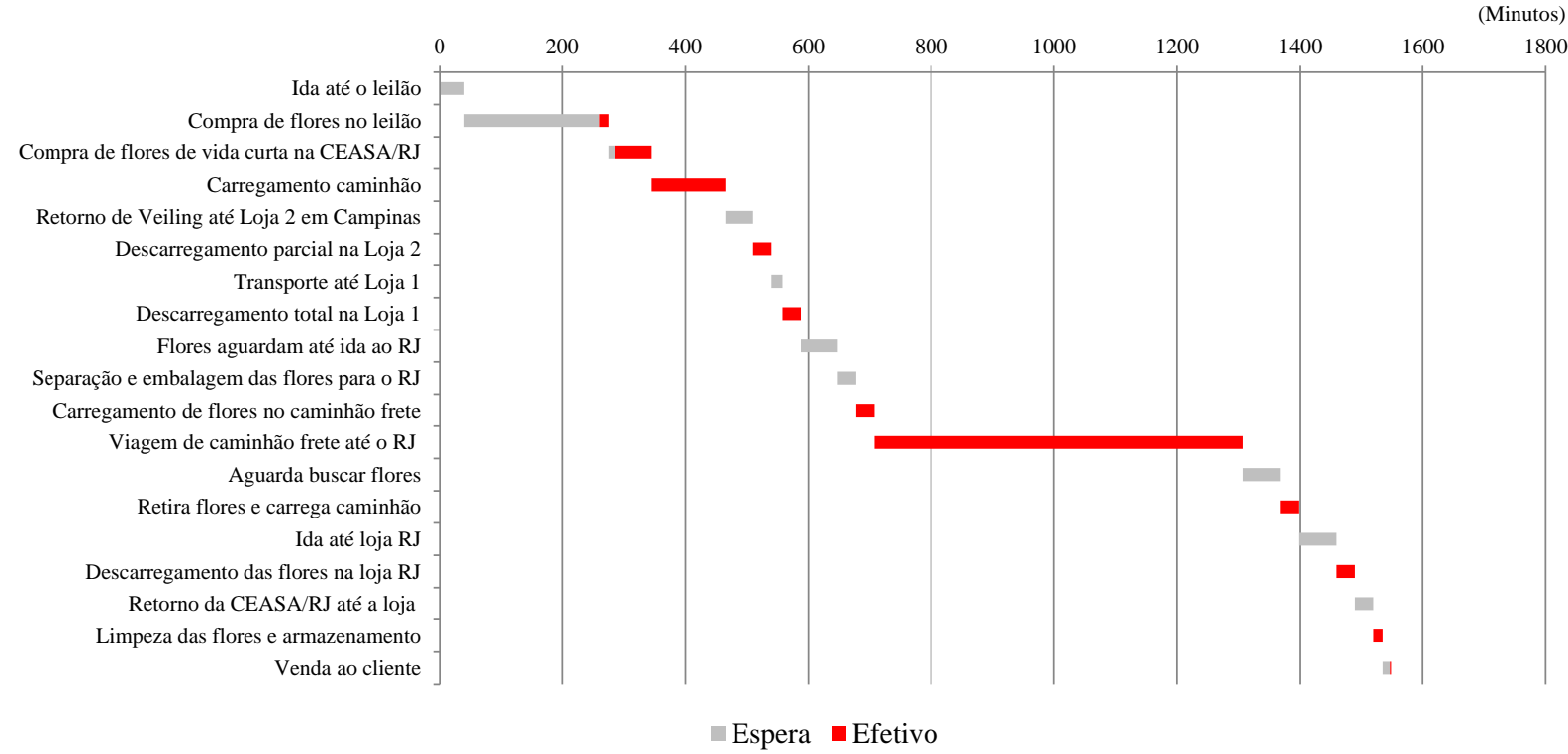

Fonte: Elaboração própria (2015)

\subsection{Resultados encontrados}

A análise do MCT original de cada loja (Figuras 8a, 9a, 10a, 11a e 12a) possibilitou o destaque de três questões principais (1) longos tempos de ida e retorno até o leilão e a compra das flores na cidade de Holambra; (2) longos tempos de espera para efetivar o transporte ou buscar as flores; e (3) modelo de frete de transporte terrestre ineficaz.

Nas Tabelas 1 e 2 encontram-se os tempos antes e depois das ações propostas no projeto. Os tempos atuais (vistos na "Visão Inicial") são longos, sobretudo nas atividades compra de flores no leilão de Holambra; espera de início de carregamento do caminhão; flores aguardando ida para o RJ; transporte de caminhão; e aguardando buscar flores. 
Tabela 1- Comparação dos tempos entre a visão inicial (atual) e a visão do projeto nas lojas Campinas 1 e Campinas 2

\begin{tabular}{lcccc}
\hline \multirow{2}{*}{ Atividade } & \multicolumn{4}{c}{ Tempo Total no Mês (minutos) } \\
\cline { 2 - 5 } & \multicolumn{3}{c}{ Loja 2 } & \multicolumn{2}{c}{ Loja 1 } \\
\cline { 2 - 5 } & Visão Inicial & Visão Projeto & Visão Inicial & Visão Projeto \\
\hline Ida até o leilão & 160 & 80 & 160 & 80 \\
\hline Compra de flores no leilão & 940 & 470 & 940 & 470 \\
\hline Compra de flores de vida curta na CEASA & 0 & 280 & 0 & 280 \\
\hline Carregamento caminhão & 480 & 240 & 480 & 240 \\
\hline Retorno de Veiling até Loja 2 em Campinas & 180 & 90 & 180 & 90 \\
\hline Retorno da CEASA até Loja 2 em Campinas & 0 & 120 & 0 & 120 \\
\hline Descarregamento parcial na Loja 2 & 120 & 60 & 120 & 60 \\
\hline Transporte até Loja 1 & 72 & 36 & - & - \\
\hline Descarregamento total na Loja 1 & 120 & 60 & - & - \\
\hline Limpeza das flores e armazenamento & 60 & 30 & 60 & 30 \\
\hline Venda ao cliente & 56 & 28 & 56 & 28 \\
\hline Total & $\mathbf{2 1 8 8}$ & $\mathbf{1 4 9 4}$ & $\mathbf{1 9 9 6}$ & $\mathbf{1 3 9 8}$ \\
\hline
\end{tabular}

Fonte: Elaboração própria (2015)

Tabela 2 - Comparação dos tempos entre a visão inicial (atual) e a visão do projeto nas lojas Vila Velha/ES, Salvador/BA e Rio de Janeiro/RJ

\begin{tabular}{|c|c|c|c|c|c|c|}
\hline \multirow{3}{*}{ Atividade } & \multicolumn{6}{|c|}{ Tempo Total no Mês (minutos) } \\
\hline & \multicolumn{2}{|c|}{ Loja Espirito Santo } & \multicolumn{2}{|c|}{ Loja Bahia } & \multicolumn{2}{|c|}{ Loja Rio de Janeiro } \\
\hline & Visão Inicial & Visão Projeto & Visão Inicial & Visão Projeto & Visão Inicial & Visão Projeto \\
\hline Ida até o leilão & 160 & 80 & 160 & 80 & 160 & 80 \\
\hline Compra de flores no leilão & 940 & 470 & 940 & 470 & 940 & 470 \\
\hline Compra de flores de vida curta na CEASA & - & 280 & - & 280 & - & 280 \\
\hline Espera início de carregamento do caminhão & 1200 & 600 & - & - & - & - \\
\hline Carregamento caminhão & 480 & 240 & 480 & 240 & 480 & 240 \\
\hline Retorno de Veiling até Loja 2 em Campinas & - & - & 180 & 90 & 180 & 90 \\
\hline Descarregamento parcial na Loja 2 & - & - & 120 & 60 & 120 & 60 \\
\hline Transporte até Loja 1 & - & - & 72 & 36 & 72 & 36 \\
\hline Descarregamento total na Loja 1 & - & - & 120 & 60 & 120 & 60 \\
\hline Flores aguardam até ida ao RJ & - & - & - & - & 8640 & 120 \\
\hline Separação e embalagem das flores & - & - & 120 & 60 & 120 & 60 \\
\hline Carregamento caminhão & - & - & 120 & 60 & 120 & 60 \\
\hline Viagem de caminhão & 12960 & 1680 & - & - & 2400 & 1200 \\
\hline Ida até o aeroporto & - & - & 84 & 42 & - & - \\
\hline Viagem de avião até a BA & - & - & 528 & 264 & - & - \\
\hline Aguarda buscar flores & 2640 & 120 & 4080 & 120 & 2160 & 120 \\
\hline Retirar flores e carregar caminhão & 120 & 60 & 120 & 60 & 120 & 60 \\
\hline Ida até loja & 68 & 34 & 140 & 70 & 248 & 124 \\
\hline Descarregamento das flores & 120 & 60 & 120 & 60 & 120 & 60 \\
\hline Retorno da CEASA até a loja & - & 120 & - & 120 & - & 120 \\
\hline Limpeza das flores e armazenamento & 60 & 30 & 60 & 30 & 60 & 30 \\
\hline Venda ao cliente & 56 & 28 & 56 & 28 & 56 & 28 \\
\hline Total (minutos) & 18804 & 3802 & 7500 & 2230 & 16116 & 3298 \\
\hline
\end{tabular}

Fonte: Elaboração própria (2015)

Visando melhorar os tempos improdutivos ou de espera, ações de correções foram propostas, e analisando-se essas atividades, estabeleceu-se que é possível reduzir o tempo de todas as operações alterando a parte comercial da aquisição das flores e a logística, especialmente no que tange a mudar o local de compras de parte das flores, tirando do Veiling Holambra a concentração da compra. 
Ericksen; Stoflet; Suri (2007) relataram que a visão de gerenciamento das atividades depois de se obter o valor de MCT é comparar a quantidade de tempo improdutivo ao tempo de valor agregado dentro do MCT. Esse tempo excessivo normalmente é muito elevado na maioria dos casos e frequentemente surpreende os gestores e funcionários e motiva-os a tomar uma ação corretiva.

A principal ação proposta foi a estratificação da compra das flores, separando-os por tempo de vida. Como já mencionado em tópico anterior, as flores de vida curta seriam compradas em outros mercados atacadistas (Cooperativas e CEASA) das respectivas cidades de venda final (Campinas, Vila Velha, Salvador e Rio de Janeiro), e para as flores de vida longa, a sugestão foi realizar as compras apenas duas vezes por mês.

Com esta ação de estratificar a compra das flores, houve uma redução de $50 \%$ do tempo de compras das flores, de 940 minutos para 470 minutos, reduzindo o custo de viagens e favorecendo a logística de distribuição de flores de vida curta que era um dos problemas no tempo de transporte. Com esta ação, a atividade de espera de início de carregamento também foi reduzida naturalmente em $50 \%$ do tempo, no caso da loja do Espírito Santo, reduzindo o tempo de 1.200 minutos para 600 minutos.

O maior impacto na redução do tempo improdutivo em porcentagem está relacionado à atividade das flores aguardando ida para o RJ. $O$ procedimento utilizado pela empresa era de realizar a compra de todas as flores no leilão de Holambra e posteriormente armazenamento na loja de Campinas por 1,5 dias e só após esta operação era realizado o carregamento do caminhão (tempo efetivo) e o transporte terrestre até a cidade do Rio de Janeiro.

O tempo de espera das flores do RJ foi reduzido em $98,6 \%$, pois com a menor quantidade de flores adquiridas em Holambra planejou-se melhor a parceria com a empresa de transporte e eliminou a espera de 1,5 dias/semana para apenas 60 minutos a cada 15 dias. Reduzir o lead time do processo ou o tempo médio de transporte, que faz parte do lead time, pode oferecer benefícios financeiros para as empresas (DULLAERT; ZAMPARINI, 2013).

Outro tempo elevado (segunda maior redução) para os três estados foi aguardando buscar flores no local de entrega, que representou $95,5 \%, 97,1 \%$ e $94,4 \%$, respectivamente. Este problema foi solucionado com duas ações, sendo que a primeira foi a contratação de melhores parceiros de transporte terrestre, no caso do ES e RJ, e para a BA a definição de um melhor horário de saída do transporte aéreo. Aktas; Ulengin (2005) relataram que o transporte afeta diretamente os custos e o lucro das empresas, a satisfação dos clientes, bem como se apresenta como um papel estratégico. Em todos os casos os valores reduziram para apenas 120 minutos/mês.

A viagem de caminhão para o Espirito Santo foi a terceira redução em porcentagem $(87,1 \%)$. Inicialmente, a empresa utilizava um parceiro de transporte 
que realiza a entrega das flores para diversas empresas no caminho de Holambra/SP até Vitória/ES, acarretando um tempo de 54 horas/semana para este transporte até o destino final. Com a redução da compra para apenas duas vezes/mês, pôde-se contratar um parceiro de transporte direto, ou seja, o tempo de transporte passou para 14 horas a cada duas semanas e esse custo mensal específico permaneceu igual. Segundo Menezes; Guimarães; Sellitto (2008), a redução no tempo de execução das atividades de transporte é de extrema importância e gera ao cliente final uma maior confiança na empresa varejista. Heydari (2014) também relata que se utilizando de empresa de transporte mais confiável, o varejista pode diminuir o lead time de seu processo.

Notou-se por estas atividades com alto lead time do processo que a empresa possui o foco das suas ações em custo e estratégia de marketing de sua marca com a maior parte da compra das flores no leilão de Holambra e não no tempo das etapas do processo e na entrega das flores aos seus clientes no menor tempo possível. Este fato ocorre de forma semelhante em outras empresas, quando as principais causas de longo lead time no processo de produção são baseadas nas políticas objetivando baixo custo e não no tempo e na falta de coordenação (GODINHO FILHO et al., 2011). Cabe salientar, com o ambiente comercial competitivo, uma das formas de atrair novos clientes é gerenciar o menor lead time possível, assim a empresa fornecedora de produtos/serviços pode entregar produtos dentro do menor tempo possível em comparação com seus concorrentes (SARKAR et al., 2015).

Há também um problema relacionado a necessidade de um valor mínimo de compra de flores no Veiling Holambra. Os compradores cadastrados precisam comprar um valor mínimo por mês para poderem efetivar suas compras. A solução proposta para tal situação foi a incorporação da atividade de venda intermediária para outras empresas do ramo de floricultura em Campinas. Assim, a empresa não precisou mais comprar flores de menor valor agregado, que normalmente são as de vida curta, e seu custo e lead time foram reduzidos. Como para as duas lojas de Campinas este tempo era o mais oneroso ao processo, com esta redução de apenas uma compra a cada 15 dias e outras melhorias nos tempos das atividades, houve uma redução de aproximadamente $30 \%$ do lead time.

Para as outras três lojas, os maiores ganhos foram as seguintes ações: mudança de transporte para um frete mais especializado; roteirização do horário de partida e chegada; e aquisição de flores de vida curta na cidade de origem da empresa, como em Cooperativas e CEASAs. Estas ações reduziram o lead time em aproximadamente $80 \%$.

Além da redução do lead time, observaram-se os ganhos com a maior flexibilidade da empresa para atender a variação no mix de produtos e o volume da demanda em períodos sazonais (datas comemorativas), e a melhoria na capacidade de cumprir prazos de entrega e consequentemente na maior confiança dos clientes. 
A confiabilidade da entrega não é importante somente para a estratégia a ser adotada para o modelo de transporte, mas pode justificar estruturas logísticas mais caras para estabelecer um baixo lead time e frequentemente com baixo custo da gestão logística (DULLAERT; ZAMPARINI, 2013).

Após a definição das propostas detalhadas de aplicação da ferramenta do QRM, buscou-se vislumbrar os impactos resultantes dessa aplicação. Considerando que o lead time é o foco absoluto da metodologia QRM, os impactos devem ser avaliados especialmente em função da redução deste (GODINHO FILHO et al., 2011). A elaboração de bons projetos para implantação de novas tecnologias é de fundamental importância para que uma empresa se mantenha competitiva frente a seus concorrentes (GONÇALVES; MADEIRA JUNIOR; RIBEIRO, 2011).

\section{CONSIDERAÇÕES FINAIS}

O objetivo principal do artigo, que foi analisar os processos logísticos de uma rede varejista de flores buscando propor ações para reduzir o lead time com base na ferramenta MCT - Manufacturing Critical-path Time foi alcançado. O caso evidenciou o potencial da ferramenta na diminuição do lead time, perfazendo a possibilidade de uma resposta mais rápida e confiável ao cliente.

A empresa se caracteriza pela alta variabilidade de produtos com perecibilidades distintas, que podem variar de dias a meses, portanto a redução do tempo das operações e dos processos logísticos é essencial para a diminuição do desperdício ou vendas perdidas, o que consequentemente influencia no lucro da empresa e na sua competitividade no mercado.

No modelo atual notou-se um horizonte de planejamento de uma semana, ou seja, semanalmente eram realizadas as compras e as entregas nos centros consumidores. $\mathrm{Na}$ análise final desta pesquisa, foi proposta a redução do lead time através de mudanças na política de transporte, específicas para cada loja, e principalmente por meio de uma divisão na compra das flores, de acordo com a duração de cada vida útil.

Com a estratégia proposta de compra por grupo de vida útil em diferentes locais (CEASAs locais, Cooperativas e Veiling Holambra), mantendo a qualidade das flores, foi possível obter redução dos custos de transporte e tempos de espera, gerando aumento na quantidade de vendas.

Esse estudo visou, em um primeiro momento, apontar o grau de influência na cadeia de distribuição de uma rede varejista de flores, e também contribuir analogamente para diagnóstico de outros setores com o mesmo tipo de gap, ou seja, desde o manuseio, transporte especial, entrega de uma linha de produtos que mantém em seu maior valor agregado a originalidade de suas características naturais. 


\section{REFERÊNCIAS}

ABAFEP. Disponível em: http://www.abafep.com.br/ - Acesso em 15.07.2016.

AKTAS, E; ULENGIN, F. Outsourcing logistics activities in Turkey. The Journal of Enterprise Information Management, v.18, n.3, p. 316-329, 2005.

http://dx.doi.org/10.1108/17410390510591996

BUENO, J. D. Terra de negócios, terra de trabalho: a produção de flores em Holambra/SP. Novos Cadernos NAEA, v. 18, n. 1, p. 183-196, 2015.

CRESWELL, J. W. Projeto de Pesquisa: Métodos Qualitativo, Quantitativo e Misto. 3. ed. Porto Alegre: Artmed, 2010.

DE SORDI, J. O. Elaboração de pesquisa científica: seleção, leitura e redação. São Paulo: Saraiva, 2013.

DULLAERT, W; ZAMPARINI, L. The impact of lead time reliability in freight transport: A logistics assessment of transport economics findings. Transportation Research Part E: Logistics and Transportation Review, v. 49, n.1, p. 190-200, 2013.

http://dx.doi.org/10.1016/j.tre.2012.08.005

ERICKSEN, P. D.; STOFLET, N. J.; SURI, R. Manufacturing critical-path time (MCT): the QRM metric for lead time. Wisconsin-Madison: Center for QRM, 2007.

FERNANDES, N. O.; CARMO-SILVA, S. Generic POLCA - A production and materials flow control mechanism for quick response manufacturing. International Journal of Production Economics, v. 104, n. 1, p. 74-84, 2006. http://dx.doi.org/10.1016/j.ijpe.2005.07.003

GODINHO FILHO, M.; MARCO, C. F.; SAGAWA, J. K.; KINOSHITA, D.; PEIXOTO, M. G. M. Proposta de aplicação da abordagem quick response manufacturing em uma empresa do setor automobilístico. XXXI Encontro Nacional de Engenharia de Produção, 2011.

GODINHO FILHO, M.; SAES, E. V. From time-based competition (TBC) to quick response manufacturing (QRM): the evolution of research aimed at lead time reduction. The International Journal of Advanced Manufacturing Technology, v. 64, n. 5-8, p. 11771191, 2013. http://dx.doi.org/10.1007/s00170-012-4064-9

GODINHO, M.; HAYASHI, A. P. RUFO, C. R. Uso da abordagem Quick Response Manufacturing para a redução do lead time em uma empresa do setor calçadista. XXXIII Encontro Nacional de Engenharia de Produção. Salvador/BA, 2013.

GONÇALVES, T. J. M.; MADEIRA JUNIOR, A. G.; RIBEIRO, A. C. Avaliação de projeto para implantação de um sistema de voip: um caso na indústria de alimentos. Revista Produção Online, v.11, n. 3, p. 668-687. 2011. http://dx.doi.org/10.14488/1676-1901.v11i3.545

HEYDARI, J. Lead time variation control using reliable shipment equipment: An incentive scheme for supply chain coordination. Transportation Research Part E, v. 63, p. 44-58, 2014. http://dx.doi.org/10.1016/j.tre.2014.01.004 
IBRAFLOR. Disponível em: http://www.ibraflor.com/ns_mer_interno.php - Acesso em 26.06.2015.

JUNQUEIRA, A. H.; PEETZ, M. D. S. O setor produtivo de flores e plantas ornamentais do Brasil, no período de 2008 a 2013: atualizações, balanços e perspectivas. Revista Brasileira de Horticultura Ornamental, v. 20, p. 115-120, 2014. http://dx.doi.org/10.14295/rbho.v20i2.727

KNAAP, A. V. 25 Anos Klok 1989 - 2014 - Veiling Holambra. São Paulo: Arpejo Comunicação Integrada, 2014.

MENEZES, T.M.; GUIMARÃES, M.G.; SELLITTO, M.A. Medição de indicadores logísticos em duas operações de montagem abastecidas por cadeias de suprimentos. Revista Produção Online, v.8, n.1, p.1-23, 2008. http://dx.doi.org/10.14488/1676-1901.v8i1.26

NEVES, M. F.; CONEJERO, M. A. Uma Contribuição Empírica para Geração de Métodos de Planejamento e Gestão. Revista de Administração (FEA-USP), v. 47, p. 699, 2012.

PIOVEZAN, L. H.; LAURINDO, F. J. B.; CARVALHO, M. M. Proposta de método para a formulação de estratégia em pequenas e médias empresas. Revista Produção Online, v. 8, n. 2, p. 1-27, 2008. http://dx.doi.org/10.14488/1676-1901.v8i2.117

SARKAR, B.; MANDAL, B.; SARKAR, S. Quality improvement and backorder price discount under controllable lead time in a inventory model. Journal of Manufactuting Systems, $v$. 35, p. 26-36, 2015. http://dx.doi.org/10.1016/j.jmsy.2014.11.012

SEBRAE, Serviço Brasileiro de Apoio à Micro e Pequena Empresa. Disponível em: <http://www.sebrae.com.br> Primeiro acesso em 4 mar. 2014.

SEIFERT, M.; SIEMSEN, E.; HADIDA, A. L.; EISINGERICH, A. B. Effective judgmental forecasting in the context of fashion products. Journal of Operations Management, v. 36, p. 33-45, 2015. http://dx.doi.org/s0272-6963(15)00015-7

SILVA, L.C.; PAIVA, P. D. O.; SANTOS, A. C. Flower and ornamental plants wholesale markets in Brazil. Ornamental Horticulture, v. 21, p. 53-62, 2015.

SONEGO, G.; BRACKMANN, A. Conservação de pós-colheita de flores. Revista Ciência Rural, v. 25, n.3, p. 473-479, 1995.

SOULÉ, F. V.; FRANÇOSO, A. B. L.; KODAMA, T. K.; BESSI, N. C.; SCHIAVON, L.; GODINHO FILHO, M. Proposta de redução de lead time na linha de produtos termoelétricos de uma pequena empresa familiar do interior paulista. Revista Produção Online, v. 16, n. 1, p. 278-312, 2016. http://dx.doi.org/10.14488/1676-1901v16i12138

\section{SURI, R. Quick Response Manufacturing: A companywide Approach to Reducing} Lead Times. Productive Press, 1998.

SURI, R. It's About Time: The Competitive Advantage of Quick Response Manufacturing. Productive Press, 2010.

SURI, R. Disponível em: <http://www.rajansuri.com/why_qrm> - Primeiro acesso em 26 jun. 2015. 
TUBINO, F; SURI, R. What kind of "numbers" can a company expect after implementing Quick Response Manufacturing? Empirical data from several projects on lead time reduction. Quick Response Manufacturing Conference Proceedings, p. 943-972, 2000.

VEILING HOLAMBRA - Disponível em http://www.veiling.com.br/cooperativa/ - Primeiro acesso em 26 jun. 2015.

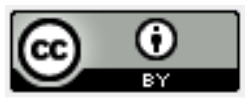

Artigo recebido em 28/11/2015 e aceito para publicação em 30/09/2016

DOl:http://dx.doi.org/ 10.14488/1676-1901.v16i4.2253 